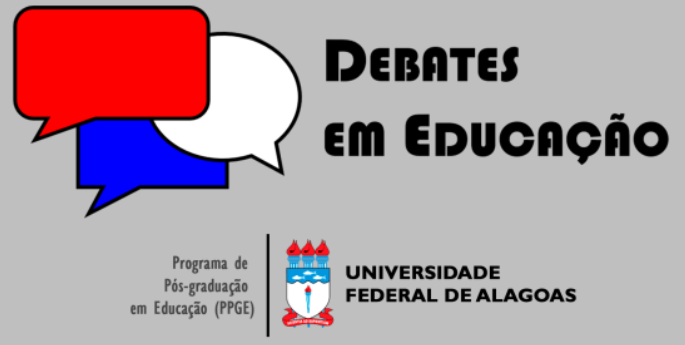

ISSN Eletrônico 2175-6600

Vol. 12 | No. 27 | Maio/Ago. | 2020

Filomena Maria Cordeiro Moita

9 iD

Universidade Estadual da Paraíba (UEPB)

filomena_moita@hotmail.com

Lucas Henrique Viana

(9) iD

Universidade Estadual da Paraíba (UEPB)

lucas_henriqk@hotmail.com

Maria Rosilene Gomes Flor

9 iD

Universidade Federal de Campina Grande (UFCG) roflor08@gmail.com

\section{O SOFTWARE GCOMPRIS E OS MULTILETRAMENTOS NO CENÁRIO ESCOLAR}

\section{RESUMO}

avanço tecnológico vem provocando mudanças nas práticas socioculturais que fazem surgir novas demandas educativas, como o desenvolvimento de multiletramentos. Nesse sentido, com base na perspectiva de professores, buscamos analisar as contribuições do software GCompris nos processos de multiletramentos de crianças de uma escola municipal de Campina Grande-PB. Trata-se de um estudo de caso, que contemplou observação, entrevistas semiestruturadas e análises técnica e pedagógica do GCompris, utilizando um instrumento desenvolvido pelo grupo de pesquisa em Tecnologia Digital e Aquisição do Conhecimento. Os dados obtidos revelaram algumas potencialidades educativas, lacunas e contribuições desse recurso para os multiletramentos e a necessidade de capacitação docente para explorar suas funcionalidades mais complexas.

Palavras-chave: Tecnologias digitais. GCompris. Multiletramentos.

\section{GCOMPRIS SOFTWARE AND MULTILITERACIES IN THE SCHOOL SCENARIO}

\section{ABSTRACT}

Technological advances have been provoking changes in socio-cultural practices that have given rise to new educational demands, such as the development of multiliteracies. In this sense, based on the perspective of teachers, we seek to analyze the contributions of the GCompris software in the multiliteracies processes of children at a municipal school in Campina Grande-PB. This is a case study, which included observation, semi-structured interviews and technical and pedagogical analysis of GCompris, using an instrument developed by the research group on Digital Technology and Knowledge Acquisition. The data obtained revealed some educational potentialities, gaps and contributions of this resource to the multiliteracies and the need for teacher training to explore its most complex functionalities.

Keywords: Digital technologies. GCompris. Multiliteracies.

Submetido em: 24/09/2019

Aceito em: 15/02/2020

Publicado em: 22/06/2020

do http://dx.doi.org/| 0.28998/2 175-6600.2020v I 2n27p744-76| 


\section{INTRODUÇÃO}

Vivemos na era da sociedade da informação, marcada pelos reflexos da facilidade de acesso às tecnologias digitais da informação e comunicação (TDIC) e de sua evolução. Entre esses reflexos, destacam-se as novas modalidades de comunicação, que usam imagens, sons, animações, vídeos, entre outras linguagens, gêneros e mídias, de forma síncrona ou assíncrona.

Esses novos meios de comunicação introduzidos pelo progresso tecnológico geram impactos em praticamente todos os ambientes, sejam eles físicos ou virtuais. Entre os ambientes físicos, vale destacar as escolas, que enfrentam cada vez mais novos desafios para atender às demandas dos alunos nativos digitais ${ }^{1}$, que necessitam de novas práticas pedagógicas para aprender.

Essas demandas se manifestam desde os primeiros anos desses alunos na escola, que desenvolvem diversas habilidades fundamentais para todo o seu processo formativo, entre elas, a leitura e a escrita, cujo processo de aquisição dessas habilidades é compreendido como alfabetização. Para Soares (2003, p. 16) "a alfabetização é um processo de representação de fonemas em grafemas, e vice-versa, mas é também um processo de compreensão/expressão de significados por meio do código escrito". Assim, para ser considerado alfabetizado, um indivíduo deve ser capaz de ler, compreender e produzir pequenos textos.

Ressalta-se, entretanto, que, devido ao fracasso desse processo nas escolas brasileiras, desde a década de 90, o MEC adotou uma série de medidas visando reduzir os índices de fracasso escolar no ciclo da alfabetização, como a aprovação da Lei de Diretrizes e Bases da Educação Nacional (LDB, n: 9394/96), que determina a matrícula de crianças no ensino fundamental, a partir dos sete anos de idade.

Além disso, os artigos 32 e 87 da LDB foram alterados pela Lei $n^{\circ}$ । I . 274/2006, que instituiu o ensino fundamental de nove anos, garantiu a matrícula de crianças com seis anos de idade e ampliou seu tempo escolar nos anos iniciais do Ensino Fundamental para desenvolver as competências relacionadas à aprendizagem da alfabetização e dos letramentos. Dessa forma, a alfabetização deixou de ser o foco da escola nos anos iniciais e deu espaço ao processo de letramento, que de acordo com Morais (20 I 2) não envolve somente a aquisição da leitura e da escrita, mas também seu uso social. Por esse motivo, a escola passou a promover o desenvolvimento de práticas de leitura e de produção de textos que se relacionem ao contexto sociocultural do aluno, apontadas pela Base Nacional Comum Curricular, como práticas diversificadas de letramentos (BRASIL, 2017).

termo letramentos tem sido utilizado no plural em trabalhos de pesquisadores como Street (20/4), Rojo $(2009,2012,2013)$ e Kleiman (20/4) com o fim de mostrar que a escola precisa, com

\footnotetext{
' Estudos como os de Prensky (20 I0), Fantin (2016) e Coelho, Costa e Neto (20।8) corroboram com a discussão de forma atualizada do uso dos termos "nativos digitais" e "imigrantes digitais", apresentando forte embasamento teórico, rigor crítico, evidências e argumentos que contribuem teoricamente para desmistificação existente em torno destes termos, sobre os quais não nos aprofundaremos neste texto.
} 
urgência, considerar as diversas práticas e os eventos de letramentos utilizados pela sociedade, assim como a multiplicidade de linguagens, textos e mídias em circulação, cuja aquisição configura o processo conhecido como multiletramentos.

Assim, o foco da escola partiu da alfabetização para um processo mais amplo e condizente com as necessidades dos alunos que nasceram e vivenciam as transformações sociais e tecnológicas da era digital, cujo significado também é extenso e envolve uma série de fatores associados ao contexto sociocultural em que vivem.

Para Rojo (2009, 2012, 2013) e Kleiman (2014) a pedagogia dos multiletramentos tem como pressuposto fundamental a implementação, no currículo escolar, de práticas que levem em conta a diversidade cultural e a multiplicidade de linguagens, gêneros textuais e mídias utilizadas por diferentes esferas da sociedade com apoio das tecnologias digitais. Assim, o uso qualificado e planejado de tecnologias digitais em sintonia com a cultura infantil e suas subjetividades na prática pedagógica amplia o cenário de desenvolvimento dos multiletramentos. Essa ampliação também gera desafios para os professores e para comunidade escolar, que precisam se atualizar e ir além dos letramentos, promovendo multiletramentos que atendam às novas demandas da sociedade, marcadas pela facilidade de acesso à informação e ao conhecimento.

Para proporcionar esses multiletramentos, os professores devem buscar recursos que sejam suficientemente didáticos e interativos para estimular os alunos a aprenderem e a desenvolverem suas habilidades de leitura, de escrita e, sobretudo, de interpretar e representar. Um exemplo desses recursos é o GCompris, um software livre que contém dezenas de atividades e jogos inerentes a diferentes áreas do conhecimento que possibilita, de forma lúdica, o desenvolvimento de multiletramentos. Nesse contexto, este artigo tem o objetivo de analisar as contribuições do software educativo GCompris nos processos de multiletramentos de crianças, de acordo com a perspectiva de professores de uma escola municipal da cidade de Campina Grande - PB, como também almeja apresentar uma análise dos seus aspectos pedagógicos e técnicos.

A seguir, apresentamos algumas considerações teóricas sobre os processos de multiletramentos, com uma breve descrição do GCompris e suas funcionalidades, a metodologia empregada neste estudo, a discussão dos resultados obtidos e as considerações finais dos autores.

\section{PROCESSO DE LEITURA E ESCRITA NO CONTEXTO DOS MULTILETRAMENTOS}

Segundo Cope e Kalantzis (2009) os multiletramentos originaram-se em 1996, com a divulgação do manifesto 'A pedagogy of multiliteracies: designing social futures' (Uma pedagogia dos multiletramentos: 
desenhando futuros sociais), produzido por um grupo de dez pesquisadores, conhecido como New London Group (Grupo de Nova Londres - GNL). Esses pesquisadores se reuniram em Nova Londres para discutir sobre os reflexos da globalização e da expansão das TDIC no contexto sociocultural e educacional e, segundo Rojo (2012, p. 12), enfatizaram em publicações de artigos, na perspectiva dos multiletramentos,

[...] a necessidade de a escola tomar a seu cargo [...] os novos letramentos emergentes na sociedade contemporânea [...] devido às novas TICS e de levar em conta e incluir nos currículos a grande diversidade de culturas já presentes na sala de aula de um mundo globalizado e caracterizada pela intolerância na convivência com a diversidade cultural, com a alteridade.

Corroborando o pensamento de Rojo, Kleiman (2014) menciona que o GNL advoga pelos multiletramentos com base na constatação de fatores relacionados aos textos em circulação na contemporaneidade, que consistem no impacto do texto digital constituído de diferentes linguagens, na crescente utilização de imagens nos textos verbais e no interesse em estudar as rápidas e sucessivas modificações nos modos de se comunicar.

Dessa forma, o termo multiletramentos está relacionado a dois tipos de multiplicidade presentes nas práticas de letramento na sociedade contemporânea, como afirma Rojo, (20 I3, p. I4): "por um lado, a multiplicidade de linguagens, semioses e mídias envolvidas na criação de significação para os textos multimodais [...] e, por outro, a pluralidade e a diversidade cultural trazidas pelos autores/leitores [...] para essa criação de significação".

Essa discussão sobre os multiletramentos, iniciada no manifesto GNL continuou com a publicação de projetos vinculados aos multiletramentos em conferências realizadas em países como China (2002), Reino Unido (2003), Espanha (2005) e África do Sul (2007) e deixou como legado o desenvolvimento de uma teoria da aprendizagem implicada em ações transformadoras que envolve a construção de significados e o respeito à subjetividade dos sujeitos (COPE e KALANTZIS, 2009).

Nesse sentido, a pedagogia dos multiletramentos envolve processos conhecidos como Experimentar, Conceitualizar, Analisar e Aplicar (COPE e KALANTZIS, 2009) que visam contemplar as especificidades das práticas socioculturais dos indivíduos que compõem o cenário escolar. Nesse contexto, cabe ao professor considerar a identidade e as subjetividades dos sujeitos, assim como sua cultura local, no sentido de transformá-las em fatores potenciais de construção de conhecimentos, de diálogo intercultural e interação, para afastar qualquer tipo de negação dessas diferenças, de exclusão e de preconceitos.

Essa ideia nos remete a Canen e a Xavier (20 I I) que contribuem para o entendimento de que o trabalho docente, na perspectiva da diversidade cultural, torna o espaço escolar um cenário com potencial significativo para formar cidadãos capazes de respeitar e valorizar a cultura do outro, sem que, para isso, tenha que negar a própria cultura, suas raízes, suas lutas, subjetividades e valores. 
Assim, a pedagogia dos multiletramentos é necessária como um novo design de aprendizagem capaz de reconhecer a interface entre a multiplicidade de culturas e de tecnologias digitais, potencializando as práticas de leitura e de escrita no contexto escolar (SANTOS e KARWOSKI, 20I8) de modo que os alunos são vistos como protagonistas nos processos de construção de conhecimentos, e suas experiências sociais são valorizadas.

Seguindo esse pensamento, é possível refletir que os multiletramentos a serem praticados nas escolas precisam contemplar a variedade de textos em circulação social na contemporaneidade, especialmente no meio digital. Lévy (1996, p. 40) afirma que "a digitalização e as novas formas de apresentação do texto só nos interessam porque dão acesso a outras maneiras de ler e compreender". Esses textos são interativos, colaborativos e utilizam diferentes mídias e linguagens, exigindo do leitor multiletramentos, novas habilidades, capacidades e práticas de compreender para construir significado.

Nesse sentido, a pedagogia dos multiletramentos deve atender ao perfil do novo aluno, que, segundo o GNL, requer demandas diferenciadas. Considerado como pertencente à geração Alfa, esse aluno é um colaborador ativo do processo de construção de conhecimentos, de textos e de outros produtos midiáticos. McCrindle (2015) citado por Oliveira e Cruz (20।6, p. 7) afirma que a geração Alfa "é a de filhos da geração $Y$, nascidos e formados inteiramente no século $X X \mid$, é a geração mais dotada materialmente e tecnologicamente alfabetizada".

Atualmente a geração Alfa é composta de crianças nascidas depois do ano de 2010, portanto é a terceira geração de nativos digitais, que têm mais acesso às tecnologias digitais, à informação e à educação formal e, como são motivadas pela curiosidade, constroem conhecimentos quando teclam e utilizam, desde cedo, recursos manuseados em outras épocas apenas por adultos.

Dessa forma, no intuito de contemplar os anseios da geração Alfa no processo de ensino e de aprendizagem, o professor deve planejar com antecedência suas aulas e selecionar a tecnologia digital disponível na escola para ser utilizada pedagogicamente, facilitando a construção de conhecimentos à luz da pedagogia dos multiletramentos.

Os estudos de Moita (2007) contribuem para que entendamos que é possível desenvolver ações pedagógicas em ambientes digitais, mídias audiovisuais ou em meios impressos, quando dizem que

\footnotetext{
a escola não é, portanto, o único espaço considerado pedagógico; outros contextos, como os games, os filmes, as revistas, as bibliotecas, os jornais, os brinquedos, os anúncios publicitários etc. podem oportunizar contextos e momentos lúdicos importantes para a construção de saberes sobre si, sobre os outros e sobre as coisas que estão ao redor, além de conhecimentos técnicos e formais (científicos). (MOITA, 2007, p. 5).
}

Assim, mesmo que muitos docentes ainda não possam ter acesso a recursos digitais na sala de aula, podem inovar suas aulas com outros recursos analógicos que estejam disponíveis, promovendo situações 
significativas de uso social da leitura, da escrita e da construção de aprendizagens, contemplando o desenvolvimento das competências relacionadas ao trabalho pedagógico com os multiletramentos.

A esse respeito, Rojo (2012) assevera que textos impressos, como jornais, revistas e livros didáticos, são constituídos de textos multissemióticos, que contêm gráficos, infográficos, imagens, entre outros aspectos que remetem aos textos de ambientes digitais e possibilitam que o leitor vá de um texto para outro, numa mesma página, e entre em contato com diferentes linguagens. Essa é uma forma de potencializar o desenvolvimento dos multiletramentos. Contudo, trazer essas inovações para o ensino da alfabetização não é uma tarefa fácil, porquanto é necessário que o professor se familiarize com as tecnologias digitais e se prepare para utilizar essas ferramentas de forma lúdica e criativa, buscando utilizar pedagogicamente suas vantagens e com certo cuidado para não utilizar essas tecnologias na perspectiva de um ensino tradicional.

Um recurso que traz diversas possibilidades pedagógicas para os processos de multiletramentos infantil e que poderia ser mais bem explorado nas escolas é o GCompris, que será apresentado no tópico a seguir.

\section{O SOFTWARE EDUCATIVO GCOMPRIS}

O acesso às tecnologias digitais não é uma realidade de todas as crianças nascidas na era digital. Considerando esse dado, ações como o 'Programa Nacional de Tecnologia Educacional' (PROINFO) e o 'Programa Banda Larga na Escola' (PBLE) vêm ampliando o acesso de estudantes de escolas públicas à internet e às tecnologias digitais. Por meio do PROINFO, muitas escolas públicas foram equipadas com laboratórios de informática, em cujas máquinas foi instalado o GCompris, um software educacional livre, que faz parte dos programas educacionais do MEC, projetado para o uso de crianças com idades entre dois e dez anos.

Esse artefato contém oito grupos de jogos, o que possibilita ao usuário mais de cem atividades, com caráter lúdico e fácil de manipular, que podem ser adaptadas, aperfeiçoadas e compartilhadas com outras pessoas sem restrições, sob os termos da Licença Pública Geral (GNU/GPL)². Nascimento (20।7) menciona que a diversidade de atividades e de jogos do GCompris torna-o versátil, no que diz respeito ao atendimento das demandas educacionais, e possibilita que professores e alunos utilizem uma gama de possibilidades em diferentes áreas do conhecimento.

O software GCompris já foi traduzido para mais de cinquenta idiomas, com uma abrangência significativa que se refletiu em seu reconhecimento internacional pela UNESCO como patrimônio cultural

\footnotetext{
${ }^{2}$ GNU/GPL - Licença Pública Geral, trata-se de licença utilizada pela maioria dos programas de software livre e de código aberto. Disponível em: https://www.gnu.org/licenses/licenses.pt-br.html. Acesso: 23 nov. 2018.
} 
de herança para a humanidade (KOSMALISKI, 20I3). Além disso, ganhou o prêmio Free Software Awards, no ano de 2003, na França, como a melhor ferramenta motivacional e educativa. Isso se deve ao fato de esse software ter uma boa usabilidade e não exigir que o usuário busque tutoriais, vídeos ou blogs para aprender a usá-lo. Por essa razão, pode ser utilizado facilmente por crianças que se encontram em processo inicial de familiarização com tecnologias digitais (SANTOS, 20I2).

Corroborando esses princípios relacionados às características e às possibilidades vinculadas ao uso de jogos digitais no contexto escolar, Alves e Nery (20I5) afirmam que esses artefatos digitais favorecem a aprendizagem de novas habilidades de forma prazerosa e divertida, estimulando ultrapassar fases, alcançar novos níveis de competências e possibilita consertar e superar erros.

No GCompris, a interação e o controle são feitos por meio do uso do mouse e de cliques em ícones e botões que aparecem na interface gráfica do menu e dos submenus, conforme demonstrado na Figura I.

Figura I - Tela do submenu das atividades de leitura do GCompris.

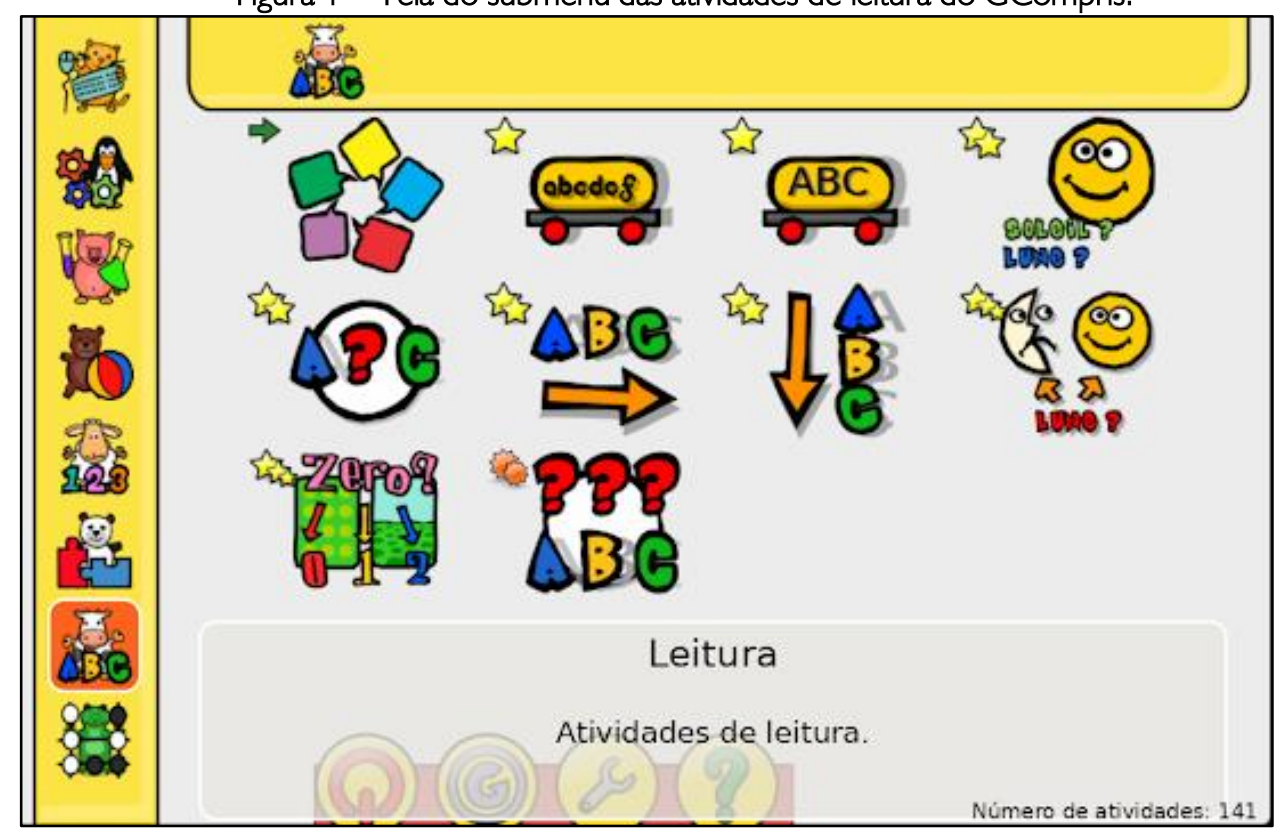

Fonte: https://gcompris.net/wiki/Manual pt-BR. Acesso em: 02 jul. 2019.

A Figura I indica que, ao redor dos ícones das atividades do submenu, há pequenos ícones que mostram a existência ou não de autofalantes e estrelas que indicam a faixa etária para a qual a atividade foi desenvolvida. Na parte inferior, há uma barra de controle com botões para sair ou desligar, informações sobre colaboradores, configuração do menu e ajuda, portanto é um sistema de informações para todo tipo de usuário, que facilita a interação entre o usuário e o software.

No site oficial do programa ${ }^{3}$, há informações e notícias atualizadas sobre o GCompris, além de um manual digital com objetivos, pré-requisitos e outras informações necessárias para a execução das

\footnotetext{
3 Site do programa GCompris: Disponível: em: https://gcompris.net/index-pt BR.html. Acesso: 02 jul. 2019.
} 
atividades e dos jogos, os quais envolvem entretenimento, exercícios interdisciplinares, raciocínio lógico, memorização, percepção visual e auditiva, escrita de palavras, produção de textos, leitura de palavras, cores, coordenação motora, criação de desenho e de animação, pintura, concentração, imagens e sons.

Com a utilização do GCompris, podem-se abordar áreas do conhecimento, como Matemática, Ciências, Geografia, Artes e Linguagem, de forma interativa, criativa e em diferentes níveis, para que a criança possa entrar em contato com a linguagem oral, visual e auditiva e com variados usos sociais da leitura e da escrita (SOUZA, 2016).

De acordo com Luz e Rodrigues (2017) quando as crianças em fase de alfabetização têm contato com diferentes recursos, como áudio, vídeo, software on-line ou off-line, no laboratório de informática, conseguem desempenhar atividades relacionadas à alfabetização, o que contribui para que possam adquirir a leitura, a escrita e os multiletramentos, de forma dinâmica e diversificada.

Nesse sentido, o uso do GCompris representa um mundo de descobertas para o aluno da era digital, que aproxima a escola de sua realidade sociocultural. Esse recurso também representa um passo importante para implementar a tecnologia educacional na escola pública. No entanto, conforme será evidenciado a seguir, ainda há muito a se caminhar para que os professores utilizem suas funcionalidades com mais aproveitamento pedagógico.

\section{METODOLOGIA}

aporte teórico tem como base os pressupostos de pesquisadores que se debruçaram nos estudos, envolvendo a pedagogia dos multiletramentos, como Rojo (2009, 2012 e 20 I3) e Street (20 I4). Todavia, abordar essa temática implica também tratar de questões relacionadas à diversidade cultural, como meio de complementar e corroborar o seu entendimento, sendo necessário recorrer a pesquisadores ligados a vieses epistemológicos diferenciados. Neste ponto, enfatizamos que nas abordagens realizadas foram respeitados os discursos e o viés epistemológico de cada área. Também buscamos as contribuições de Alves e Nery (20l5), Moita (2007), Soares (2003), entre outros pesquisadores.

Metodologicamente, este trabalho se configura como um estudo de caso, no qual realizamos observação da prática pedagógica de quatro professoras durante o período de um mês, sendo que em cada turma realizou-se a observação de duas aulas com duração de cinquenta minutos cada uma. Após a observação, realizamos uma entrevista semiestruturada com cada uma das professoras, seguindo um roteiro como guia para coletar dados que nos proporcionassem analisar as contribuições do software GCompris nos processos de multiletramentos de crianças, de acordo com a perspectiva das professoras. O referido roteiro foi composto por oito questões, abordando o perfil das professoras, suas concepções 
acerca do software GCompris, no que diz respeito à frequência de utilização e contribuição para os processos de multiletramentos e aquisição da leitura e da escrita. A partir dessas questões, a entrevista foi desenvolvida, sendo solicitados esclarecimentos mais específicos quando as professoras respondiam de forma confusa, ou incompleta, almejando assim coletar os dados de forma clara na busca de atingir os objetivos do estudo.

A escolha desta escola para o desenvolvimento desta pesquisa se deve ao fato de a instituição ser equipada com laboratório de informática e as turmas com suas respectivas professoras utilizarem com frequência o software GCompris, instalado em todas as máquinas.

A partir da avaliação deste software, em seus aspectos técnicos e pedagógicos, é possível assessorar o planejamento do professor para usar essa tecnologia digital com crianças, fornecendo dados relevantes sobre atividades/jogos e seus respectivos níveis de desafios, assim como suas lacunas.

Para realizar a avaliação do GCompris, foi utilizado um instrumento que está sendo desenvolvido pelo grupo de pesquisa em Tecnologia Digital e Aquisição do Conhecimento (TDAC), cuja versão beta pode ser consultada em Viana (20 17). Sua construção embasou-se nas considerações teóricas de autores que abordam o uso, construção e avaliação da aplicabilidade dos games na educação, como Savi et al. (20।0), Gee (20।0) e Schuytema (2008).

Assim, seguindo o instrumento de avaliação do grupo TDAC, analisamos sete critérios pedagógicos do GCompris: identidade, produção/personalização, interatividade, ferramentas inteligentes, problemas bem estruturados, desafio e consolidação e frustração prazerosa, conforme mostra o Quadro I.

\begin{tabular}{|c|c|}
\hline \multicolumn{2}{|c}{ Quadro I - Análise dos aspectos pedagógicos do software GCompris. } \\
\hline Critérios pedagógicos & \multicolumn{1}{|c|}{ Características apresentadas pelo GCompris na análise pedagógica } \\
\hline Identidade & $\begin{array}{l}\text { Apresenta elementos relacionados ao mundo real do usuário; não apresenta situações } \\
\text { relacionadas à violência; possibilita construir uma boa relação com o usuário, promovendo } \\
\text { o desenvolvimento de suas aprendizagens. }\end{array}$ \\
\hline Produção/personalização & $\begin{array}{l}\text { Ajuda o professor a criar e a salvar as próprias atividades; possibilita selecionar o idioma, a } \\
\text { quantidade de zoom e habilitar ou desabilitar o modo tela cheia e efeitos sonoros; } \\
\text { possibilita que o adulto personalize as atividades/jogos que pretende disponibilizar para a } \\
\text { criança, selecionando-as por nível, faixa etária, habilidade, entre outras opções de seleção. }\end{array}$ \\
\hline Interatividade & $\begin{array}{l}\text { Estimula a colaboração e a cooperação entre usuários, fornecendo meios de comunicação } \\
\text { entre eles, através da atividade "Converse com seus amigos". }\end{array}$ \\
\hline Ferramentas inteligentes & $\begin{array}{l}\text { Compartilha informações com o usuário; disponibiliza a descrição, o objetivo e os pré- } \\
\text { requisitos e ajuda em cada atividade/jogo. }\end{array}$ \\
\hline Problemas bem estruturados & $\begin{array}{l}\text { As atividades/jogos estão disponíveis em níveis de dificuldade, que iniciam com um nível } \\
\text { mais fácil e vão ficando mais difíceis à medida que o usuário avança, possibilitando o } \\
\text { desenvolvimento e a utilização progressiva de habilidades. }\end{array}$ \\
\hline Desafio e consolidação & $\begin{array}{l}\text { A cada nível presente no GCompris, os desafios avançam em nível de dificuldade e, } \\
\text { conforme o usuário completa-os, diversas aprendizagens são revisitadas, e outras são } \\
\text { consolidadas. }\end{array}$ \\
\hline
\end{tabular}




\begin{tabular}{|c|l|}
\hline \multirow{3}{*}{ Frustração prazerosa } & $\begin{array}{l}\text { Em alguns de seus jogos, o GCompris dá feedbacks aos seus usuários-imagens de flor, } \\
\text { palhaço ou leão sorrindo - quando ele acerta, ou com aspecto triste quando erra. Porém, } \\
\text { quando o usuário perde todas as chances de acertar em um jogo, ele é automaticamente } \\
\text { direcionado para seu início, sem nenhuma informação que o motive a voltar a jogar. Essa } \\
\text { é uma lacuna pedagógica do software. }\end{array}$ \\
\hline
\end{tabular}

Fonte: Elaborado pelos autores (20 I8).

Quadro I apresenta, de forma sucinta, algumas características pedagógicas do software GCompris, que obteve uma avaliação positiva especialmente por incorporar alguns princípios de aprendizagem presentes nos bons jogos, apontados por Gee (20 I0) e Schuytema (2008). Assim, a cada desafio solucionado no GCompris, o jogador é recompensado com uma "subvitória", que o motiva a continuar a jogar e a aprender (SCHUYTEMA, 2008). Entretanto, além dessas características pedagógicas, foi possível notar que a impossibilidade de o jogador retornar ao jogo a partir do momento ou do local onde ele errou se caracteriza como uma lacuna pedagógica que pode gerar desmotivações e prejudicar a experiência de aprendizagem do usuário.

No Quadro 2, elencamos uma síntese das caraterísticas técnicas do GCompris obtidas a partir da análise realizada. Considerando que se trata de um software projetado para ser utilizado por crianças com faixa etária entre dois e dez anos de idade, de um modo geral, ele apresenta características técnicas que favorecem o seu uso por usuários com esse perfil.

Quadro 2 - Análise dos aspectos técnicos do software GCompris.

\begin{tabular}{|c|l|}
\hline \multicolumn{1}{|c|}{ Quadro 2 - Análise dos aspectos técnicos do software GCompris. } \\
\hline Critérios técnicos & \multicolumn{1}{|c|}{ Características apresentadas pelo GCompris na análise técnica } \\
\hline Interface & $\begin{array}{l}\text { Apresenta diferentes interfaces gráficas, informações disponíveis em ícones grandes, efeitos } \\
\text { visuais em alta definição e com cores fortes, tornando-se atraente e motivador. }\end{array}$ \\
\hline Efeitos sonoros & $\begin{array}{l}\text { Oferece uma boa experiência auditiva; contém fundo musical, efeitos sonoros e áudio com } \\
\text { falas e locuções descritivas em algumas atividades/jogos, que estimulam a interação, a emoção } \\
\text { e a compreensão das atividades/jogos. }\end{array}$ \\
\hline Controle & É comandado a partir do mouse e do teclado, fato que lhe confere facilidade de operação. \\
\hline Jogabilidade & $\begin{array}{l}\text { Proporciona situações positivas de contato; apresenta as atividades/jogos em níveis crescentes } \\
\text { de dificuldade e uma boa resposta aos comandos dados no teclado ou em clicks no mouse. }\end{array}$ \\
\hline Usabilidade & $\begin{array}{l}\text { Tem um sistema simples, com mecanismos fáceis de controlar; mantém a curiosidade do } \\
\text { usuário e busca motivá-lo. }\end{array}$ \\
\hline Auxílio e dicas & $\begin{array}{l}\text { Disponibiliza informações e ajuda no momento em que o usuário solicita, tornando-se fácil } \\
\text { de usar. }\end{array}$ \\
\hline Compatibilidade & $\begin{array}{l}\text { É compatível com os sistemas operacionais Linux, Windows, Mac OSX e Android; pode ser } \\
\text { baixado em versões pagas e gratuitas no site oficial do programa. }\end{array}$ \\
\hline Fon
\end{tabular}

Fonte: Elaborado pelos autores (20 I8).

Diante do exposto, a avaliação dos critérios pedagógicos e técnicos fornece dados significativos, que possibilitam perceber que o GCompris é um software educativo com potenciais contribuições para os 
processos de ensino e aprendizagem infantil. De posse dessas informações, cabe agora conhecer como esse software é utilizado e qual o sentido que as professoras do ciclo da alfabetização atribuem ao seu uso, no que diz respeito aos processos de multiletramentos.

\section{$5 \quad$ RESULTADOS E DISCUSSÃO}

Com o intuito de obter dados para este estudo, observamos a prática pedagógica de quatro docentes quando utilizavam o software GCompris com seus alunos do ciclo da alfabetização. Nas aulas observadas, que duraram em média cinquenta minutos cada uma, verificamos que as professoras sempre iniciam as ações no laboratório de informática acessando o GCompris e disponibilizando atividades/jogos iguais para todos os alunos, dando as orientações necessárias para a realização delas, a fim de estimular a autonomia da criança.

A primeira atividade/jogo proposta pelas professoras é sempre de leitura ou escrita. Quando os alunos concluem, comunicam à professora, que, por sua vez, orienta-os sobre como devem proceder. Nesse aspecto, as ações adotadas por cada professora têm um diferencial e estão diretamente relacionadas à faixa etária da criança e ao seu nível de aprendizagem. Quando a aula terminava, as crianças sempre faziam comentários, como: "Ah, já acabou?"; "Vamos ficar mais!"; "Mas eu nem terminei ainda!"; "Tia, não deu tempo eu jogar!". Analisando essa questão, convém destacar que esses sentimentos de emoção, de motivação e de divertimento dão origem ao "aprender brincando" e são resultantes dos efeitos provocados pelos bons jogos, que em atividades bem planejadas e associadas ao contexto social do usuário favorecem novas aprendizagens (GEE, 20I0).

Ressaltamos que, apesar dos benefícios acima destacados, observamos também algumas lacunas, como por exemplo, no planejamento pedagógico de uma das professoras, ao permitir que a turma utilizasse o GCompris livremente, escolhendo uma atividade/jogo de sua preferência, sem algum objetivo pedagógico específico. Esse fato indica que o GCompris foi utilizado como mero recurso de entretenimento e ocupação do tempo ocioso das crianças, cujas potencialidades são subestimadas.

Essa atitude é contrária ao papel que deveria ser exercido pela escola e pelos docentes, ao usarem as tecnologias digitais - o de orientar a construção de conhecimentos por meio delas, para promover o desenvolvimento de competências e habilidades. A BNCC e os Artigos 32 e 35 da LDB mencionam que as práticas pedagógicas devem ter como foco principal o desenvolvimento de competências "por meio da indicação clara do que os alunos devem saber [...] e, sobretudo, do que devem 'saber fazer'” (BRASIL, 20 17). Isso reforça a importância do planejamento escolar e de deixar claro para os alunos os objetivos das atividades pedagógicas desenvolvidas. 
Logo depois das observações, foram realizadas as entrevistas com as docentes participantes da pesquisa, com o intuito de conhecer suas concepções acerca do uso do software educativo GCompris nos processos de leitura, escrita e multiletramentos de crianças em processo de alfabetização.

Os dados coletados revelam que as professoras possuem formação em nível superior para exercerem a função docente, sendo que 75\% têm Especialização e 25\%, graduação em Pedagogia. Grande parte dessas profissionais, 75\%, tem entre 41 e 50 anos de idade, o que indica que elas nasceram antes da década de 1980, fato que, no contexto da era da informação, caracteriza-as como pessoas sábias digitais, conforme Prensky (20 I0). Outros 25\% estão inseridos na faixa etária de 31 a 40 anos de idade.

Convém enfatizar que o fator idade não determina a forma como as professoras interagem com o software, visto que uma delas, com idade entre 4I e 50 anos, usa o GCompris duas vezes por semana, enquanto as outras participantes o utilizam semanalmente. Esse fato revela que tanto a professora quanto seus alunos gostam de utilizar o GCompris, explorando as possibilidades de uso e as contribuições que esse software promove nos processos de multiletramentos das crianças.

No que diz respeito ao uso específico do GCompris, no processo de uso social da leitura e de escrita, as professoras participantes da pesquisa consideram que esse software possibilita a construção de aprendizagens e de multiletramentos de forma lúdica. Além disso, mencionam que "a diversidade de atividades e de propostas educacionais" favorece o desenvolvimento de habilidades motoras e cognitivas, como concentração e memória visual, o que torna esse recurso eficiente e atraente para a criança.

Essas falas comuns às professoras vão ao encontro do que discute Gee (2010) quando menciona que os games são recursos eficazes para fazer com que seus usuários aprendam e se divirtam por meio de seus desafios. Entretanto, nem sempre esses artefatos dispõem de narrativas que atendam às exigências do setor educacional. Por esse motivo, é importante que conheça as características do game a ser utilizado em sala de aula, assim como os objetivos que se deseja atingir com seu uso. Nessa perspectiva, o professor deve fazer um planejamento prévio da aula, incluindo como recurso o GCompris, para que possa usufruir das suas potenciais contribuições. Para isso, deve selecionar as atividades/jogos de acordo com o conteúdo a ser trabalhado na sala de aula, dando significado à sua ação pedagógica.

Quanto às atividades/jogos propostas no GCompris, as falas das professoras apontam que elas favorecem os processos de aquisição da leitura, da escrita e dos multiletramentos de forma mais fácil e prazerosa para a criança. De acordo com Neto et al. (2013, p. I5I) "as práticas de letramento devem estar implicadas com a multiplicação de linguagens na produção de textos multimodais e com a pluralidade e diversidade cultural constitutivas dos sujeitos".

Vale ressaltar que nas atividades/jogos do GCompris, o usuário se depara com o uso simultâneo de multimodalidades de linguagens, como imagem estática e em movimento, efeito sonoro, música, áudio, 
linguagem verbal, expressão matemática, escrita Braille, além de outros aspectos que remetem o usuário a diferentes linguagens e culturas e favorecem o processo de multiletramentos com crianças.

Em virtude da grande quantidade de atividades contidas no GCompris, e da dificuldade em analisar todas elas à luz da pedagogia dos multiletramentos, o que seria inviável tendo em vista a extensão das páginas deste estudo, procedemos à análise de atividades/jogos mais relacionadas à prática de leitura e escrita, pois observamos que estas eram as mais acessadas pelas professoras com suas turmas.

Dessa forma, foram contempladas as atividades/jogos: Converse com seus amigos; Seu editor de textos; Palavras cadentes; Cores; Nome da imagem; Monte um quebra cabeça; Tuxpaint; Prática de leitura; Crie um desenho ou animação que, ao serem analisadas tendo em vista os pressupostos da teoria dos multiletramentos, revelaram que possuem elementos que permitem ao docente trabalhar sob essa perspectiva.

Durante o período de observação, verificamos que as professoras dão preferência ao uso do software GCompris nas máquinas do laboratório de informática, o que indica que elas restringem o trabalho com tecnologias digitais e com os multiletramentos ao uso deste recurso. Apesar de tal restrição, verificamos vantagens associadas ao uso deste software em comparação a outros, pois o mesmo funciona off-line, constituindo um fator que impulsiona a sua utilização.

As professoras mencionaram que os níveis de dificuldade progressivos, presentes nas atividades do GCompris, possibilitam trabalhar com os diferentes níveis de aprendizagem das crianças, fator que se reflete de forma positiva em seu desempenho escolar. De acordo com Schuytema (2008, p. 176) a diversidade de desafios é uma característica relevante de bons jogos, que devem oferecer ao usuário "uma gama de desafios relacionados, mas variados, com uma base compartilhada de habilidades; à medida que o jogador progride no game, ele aumenta as habilidades [...] ele pode ter sucesso".

No que diz respeito às contribuições que podem ser atribuídas ao GCompris, como um recurso facilitador do processo de leitura, de escrita e de multiletramentos, constatamos, por meio das falas das professoras, as diversas funcionalidades e as potencialidades que este artefato digital possui, como a capacidade de contribuir no desenvolvimento da consciência fonológica, da leitura e, por conseguinte, da fluência na leitura, conforme mostra o Gráfico I. 


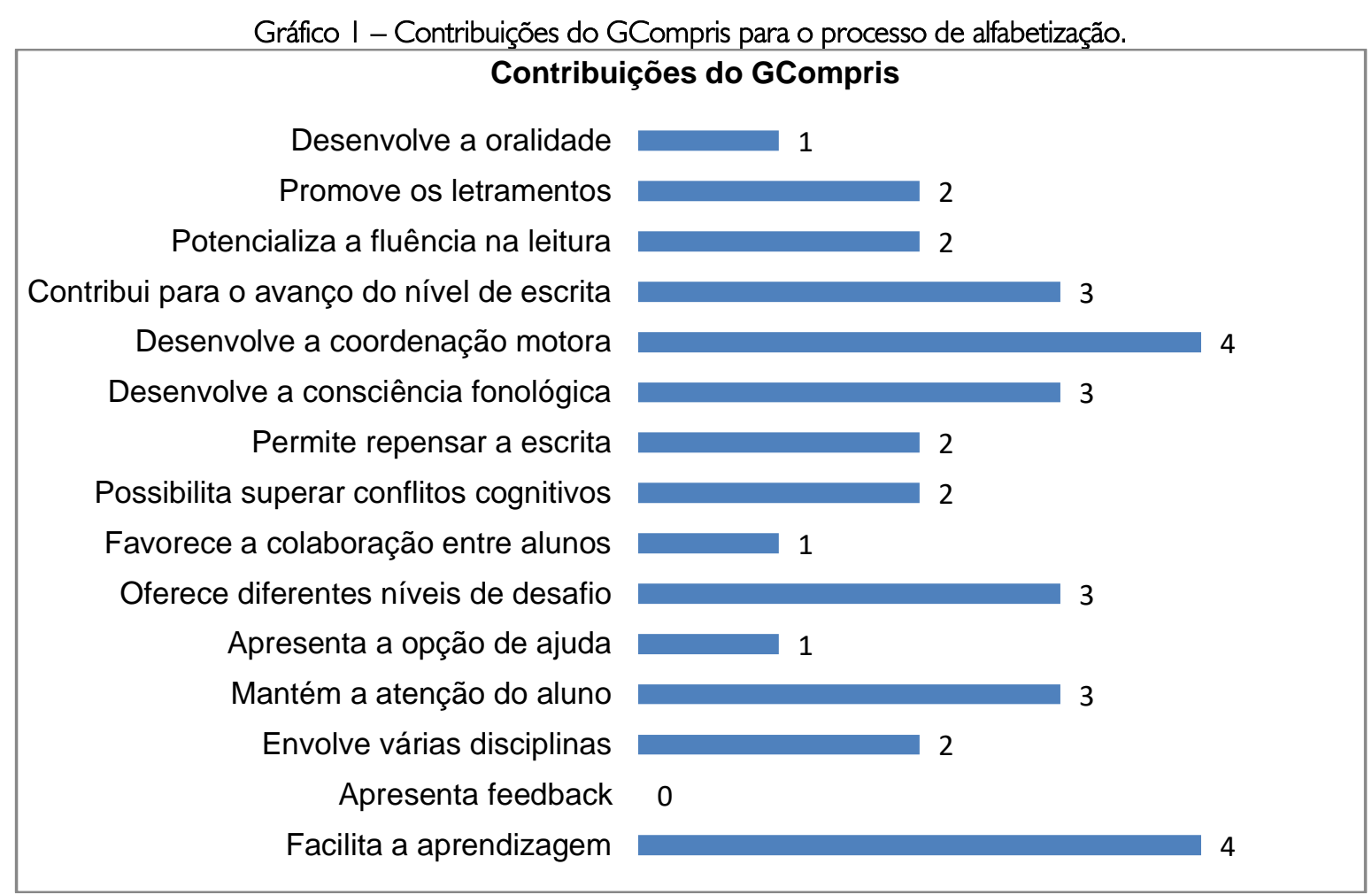

Fonte: Elaborado pelos autores, com base nos dados coletados (20 I 8).

Somando as respostas das professoras alfabetizadoras, dadas ao se analisar as contribuições do GCompris por meio das opções que lhes foram fornecidas, podemos destacar que elas concordaram com a maioria, exceto a opção "apresenta feedback".

Considerando a avaliação pedagógica e técnica apresentada e a observação das aulas com o uso do GCompris no laboratório de informática, podemos afirmar que o feedback oferecido aos usuários ainda apresenta lacunas, especialmente em seu papel de motivá-los a voltar a jogar, caso percam. Além disso, acreditamos que o acesso ao feedback individual do aluno ou da turma pelas docentes ainda parece complexo, ou trabalhoso, uma vez que exige a realização de cadastros no software. Essas opções exigem conhecimentos das docentes a respeito da administração do GCompris, que, nem sempre, são dados em cursos de formação, que, muitas vezes, só focam sua execução e deixam de lado algumas de suas potencialidades que podem facilitar a aprendizagem do aluno e o trabalho do professor.

Cabe destacar que o GCompris contribui para o processo de aquisição da escrita e possibilita que a criança pense em sua escrita, corrija seus erros, utilize letras e sílabas para formar palavras e identifique as letras do alfabeto. Essa ação de escrever teclando estimula a atenção da criança para que ela escolha as letras que vai usar o que exige dela decisões sobre como escrever, favorecendo seu avanço no processo de aquisição de escrita. A propósito disso, vale destacar a fala de Morais (2012, p. I40) quando enuncia:

[...] o fato de dispor de todas as letras do alfabeto à sua frente também torna um pouco menos complexa a tarefa de escrever palavras, porque a criança, ao identificar as letras, pode fazer associações com experiências prévias que teve com palavras que contêm a mesma letra [...] caso já tenha uma hipótese de escrita avançada, vai poder centrar sua atenção na busca das letras exatas, que servem para notar os sons que está analisando. 
As informações adquiridas com as professoras denotam que elas têm uma concepção positiva sobre o uso do GCompris. A análise dos dados também deixa claro que a utilização do GCompris contribui para os processos de multiletramentos, leitura e escrita de crianças, mostrando que essas contribuições se estendem por outras áreas do conhecimento, desenvolvendo processos cognitivos, emocionais e motores na criança. Contudo, vale ressaltar que a utilização do software por si só não garante o trabalho com multiletramentos, sendo fundamental que o professor atue de acordo com os pressupostos desta teoria conforme discutido neste estudo.

\section{CONSIDERAÇÕES FINAIS}

Este estudo, que teve como objetivo analisar as contribuições do software educativo GCompris nos processos de multiletramentos de crianças, de acordo com a perspectiva de professores de uma escola municipal da cidade de Campina Grande - PB, nos levou a tecer algumas considerações a respeito da relação entre tecnologia e prática docente no cenário escolar.

Considerando os avanços tecnológicos e a sua influência no meio social, percebe-se uma crescente necessidade de uma adaptação por parte das escolas, para que possam vivenciar essa nova realidade e aproveitar os seus impactos benéficos para a aprendizagem, de modo a atender os interesses da criança e promover o desenvolvimento dos multiletramentos.

Além disso, esta pesquisa revela a necessidade de que o professor acompanhe as mudanças tecnológicas, adote uma postura reflexiva de sua prática pedagógica, conheça os recursos digitais disponíveis na escola, analise as possibilidades de uso e de integração dessas tecnologias com os conteúdos curriculares e, especialmente, planeje o uso desses artefatos, de modo a proporcionar a produção de um conhecimento útil e eficaz para os alunos.

As considerações realizadas ao longo do texto demonstraram que o GCompris é considerado pelos docentes participantes da pesquisa um recurso pedagógico que contribui para o processo de leitura, escrita e multiletramentos de crianças, que reflete, em benefícios fundamentais para o desenvolvimento de suas aprendizagens. As atividades/jogos favorecem o trabalho da consciência fonológica e da fluência na leitura, o reconhecimento das letras do alfabeto, a superação de conflitos cognitivos e possibilitam a aquisição do sistema de escrita alfabética e dos multiletramentos. Também oferece um bom suporte de uso, interface agradável e níveis de desafios estimulantes, que favorecem a interatividade entre os usuários e autonomia ao docente na produção de atividades.

Ressaltamos que o professor deve considerar, também, as lacunas desse software, de modo a realizar um planejamento que permita superar práticas tradicionais da educação transmissiva e possibilitar que o professor inove sua prática, tornando o processo de ensino e aprendizagem mais prazeroso no 
sentido de atender a contento às necessidades e às expectativas do aluno da era digital, como é o caso dos multiletramentos.

Portanto, a pedagogia dos multiletramentos está diretamente ligada ao papel da escola, e nesse sentido, é fundamental que se aproxime da realidade da criança e de suas subjetividades que, nem sempre, são contempladas nas práticas pedagógicas comuns ao ensino de caráter tradicional. Assim, é possível entender os modos como essas culturas se manifestam e funcionam, promovendo multiletramentos que contribuam para a produção de conhecimentos plurais, éticos, democráticos, críticos e interativos.

\section{REFERÊNCIAS}

ALVES, Lynn; NERY, Jesse. (orgs.). Jogos eletrônicos, mobilidades e educações: trilhas em construção. Salvador: EDUFBA, 2015.

ANDRÉ, Marli; GATTI, Bernadete A. Métodos qualitativos de pesquisa em Educação no Brasil: origens e evolução. In: Metodologias da Pesquisa Qualitativa em Educação:teoria e prática. Petrópolis: Vozes, 20 10. Disponível em: https://www.uffs.edu.br/pastas-ocultas/bd/pro...pesquisa-e...pesquisa.../file. Acesso em: 06 ago. 2018.

BRASIL. Ministério da educação e cultura. Lei de Diretrizes e Bases da Educação Básica - Lei n 9394/96. Disponível em: http://portal.mec.gov.br/seesp/arquivos/pdf/lei9394 Idbnl.pdf. Acesso em: 09 set. 2019.

BRASIL. Lei No I I.274/2006. Disponível em: https://www2.camara.leg.br/legin/fed/lei/2006/lei- I I 2746-fevereiro-2006-540875-publicacaooriginal-42348-pl.html. Acesso em: 09 Set. 2019.

BRASIL. Ministério da Educação. Base Nacional Comum Curricular: educação é base. Brasília, 2017. Disponível em: http://basenacionalcomum.mec.gov.br/abase. Acesso em: 10 jun. 2019.

CANEN, Ana; XAVIER, Giseli Pereli. Formação continuada de professores para a diversidade cultural: ênfases, silêncios e perspectivas. Revista Brasileira de Educação. v. 16, n. 48, 201 I. Disponível em: http://www.scielo.br/pdf/rbedu/v16n48/v16n48a07.pdf. Acesso em: 10 mai. 2019.

COELHO, Patricia Margarida Farias; COSTA, Marcos Rogério Martins; NETO, João Augusto Mattar. Saber digital e suas urgências: reflexões sobre imigrantes e nativos digitais. Educação e Realidade. v. 43, n. 3, 2018 . Disponível em: http://www.scielo.br/pdf/edreal/v43n3/2175-6236-edreal-2175623674528.pdf. Acesso em: I 4 jan. 2020.

COPE, Bill; KALANTZIS, Mary. Multiliteracies: new literacies, new learning. 2009. Disponível em: http://newlearningonline.com/files/2009/03/m-litspaper I 3apr08.pdf. Acesso em: 29 ago. 2019.

FANTIN, Monica. "Nativos e imigrantes digitais" em questão: crianças e competências midiáticas na escola. Revista Passagens. v. 7, v. I, 2016. Disponível em:

http://www.periodicos.ufc.br/passagens/article/view/3652. Acesso em: 14 jan. 2020.

GCompris. Disponível em: https://gcompris.net/index-pt_BR.html. Acesso em: 02 jul. 2019.

GEE, James Paul. Bons Videojogos + Boa Aprendizagem. Coletânea de ensaios sobre os videojogos, a aprendizagem e a literacia. Tradução de Maria de Lemos Teixeira. Portugal: Edições Pedago, 20 I0. 
KLEIMAN, Angela B. Letramento na contemporaneidade. Bakhtiniana. São Paulo: UNICAMP, 2014. Disponível em: http://www.scielo.br/pdf/bak/v9n2/a06v9n2.pdf. Acesso em: 16 mai. 2019.

KOSMALISKI, Bárbara Carvalho. O Software GCompris Apoiando A Aprendizagem:estudo de caso com criança com síndrome de Down. Trabalho de conclusão de Curso de Especialização em Mídias na Educação. Universidade Federal do Rio Grande do Sul. Porto Alegre, 20 I3. Disponível em: https://www.lume.ufrgs.br/handle/I0183/9594I. Acesso em 16 mai. 2019.

LÉVY, Pierre. O que é o virtual? Tradução de Paulo Neves. São Paulo: Editora 34, 1996.

LUZ, Gládis Nunes da; RODRIGUES, Alessandra Pereira. O laboratório de informática e a alfabetização. In: TAROUCO, Liane Margarida Rockenbach; ABREU, Cristiane de Souza (Org.). Mídias na Educação:a pedagogia e a tecnologia subjacentes.Porto Alegre: Editora Evangraf: Criação Humana, UFRGS, 2017.

MOITA, Filomena Maria Gonçalves da Silva Cordeiro. Game on: jogos eletrônicos na escola e na vida da geração@. Campinas-SP: Alínea, 2007.

MORAIS, Artur Gomes de. Sistema de Escrita Alfabética. São Paulo: Melhoramentos, 2012.

NASCIMENTO, Cátia Almeida. O Uso do Software GCompris Como Ferramenta Pedagógica no Processo de Ensino e Aprendizagem em uma Perspectiva Inclusiva. Dissertação (Mestrado em Educação). Universidade de Brasília, 2017. Disponível em: http://repositorio.unb.br/handle//0482/31702. Acesso em: 13 mai. 2019.

NETO, Adolfo Tanzi (et al.). Multiletramentos em ambientes educacionais. In: ROJO, Roxane (org.). Escol@ Conectada: os multiletramentos e as TICS. I. ed. São Paulo: Parábola, 20 I3.

OLIVEIRA, Verônica Alves de; CRUZ, Breno de Paula Andrade. Geração Alfa e As Possibilidades de Pesquisas Futuras em Marketing. XI Congresso Internacional de Administração e Marketing da ESPM e XI Simpósio Internacional de Administração (20 I 6). Disponível em: http://ocs.espm.br/index.php/simposio2016/C20 16/paper/view/33. Acesso em: I 5 dez. 2018.

PRENSKY, Marc. "O aluno virou especialista". In: GUIMARÃES, Camila. Revista Época.20 I0. Disponível em: http://revistaepoca.globo.com/Revista/Epoca/0,,EMII539|8- I5224,00MARC+PRENSKY+O+ALUNO+VIROU+O+ESPECIALISTA.html. Acesso em: 12 jan. 2020.

ROJO, Roxane. Pedagogia dos multiletramentos: diversidade cultural e de linguagens na escola. In: ROJO, Roxane; MOURA, Eduardo (orgs.). Multiletramentos na Escola. São Paulo: Parábola, 2012.

ROJO, Roxane. Letramentos Múltiplos, Escola e Inclusão Social. São Paulo: Parábola, 2009.

ROJO, Roxane. (org.). Escol@ Conectada: os multiletramentos e as TICS. I. ed. São Paulo: Parábola, 2013.

SANTOS, Jucélio Soares dos. Análise de Qualidade do GCompris:software que auxilia o processo de ensino-aprendizagem e desenvolvedor de habilidades de crianças com dislexia. 20 I2. Disponível em: https://www.webartigos.com/artigos/analise-de-qualidade-do-gcompris-software-que-auxilia-o-processode-ensino-aprendizagem-e-desenvolvedor-de-habilidades-de-criancas-com-dislexia/84180. Acesso em: 13 jun. 2019.

SANTOS, Wagno da Silva; KARWOSKI, Acir Mário. Pedagogia dos multiletramentos: desafios e perspectivas na docência. Evidência. v. 14, n 14, 20 I8. Disponível em: https://www.uniaraxa.edu.br/ojs/index.php/evidencia/article/view/580. Acesso em: 22 ago. 2019. 
SAVI, Rafael. et al. Proposta de um modelo de avaliação de jogos educacionais. Revista Renote: novas tecnologias em educação. v. 8. n: 3. Rio Grande do Sul, 20 I0. Disponível em:

https://seer.ufrgs.br/renote/article/view/I 8043. Acesso em: 22 jun. 2018.

SCHUYTEMA, Paul. Design de Games: uma abordagem prática. Tradução de Cláudia Mello Belhassof. São Paulo: Cengage Learning, 2008.

Sistema Operacional GNU. Disponível em: https://www.gnu.org/licenses/icenses.pt-br.html. Acesso em: 23 nov. 2018.

SOARES, Magda. Alfabetização e Letramento. São Paulo: Contexto, 2003.

SOUZA, Carmen Gorete Duarte de. Formação Continuada de Professores: incentivando a utilização do software GCompris em sala de aula. Dissertação (Mestrado Acadêmico em Ensino). Centro Universitário Univates. Lajeado, 2016. Disponível em:

https://www.univates.br/bdu/bitstream/I0737/I | 40/I/2016CarmemGoreteDuartedeSouza.pdf. Acesso em: 13 mai. 2019.

STREET, Brian Vincent. Letramentos Sociais: abordagens críticas do letramento no desenvolvimento, na etnografia e na educação. São Paulo: Parábola Editorial, 2014.

VIANA, Lucas Henrique. O Minecraft no processo de ensino e aprendizagem da geometria espacial de posição. Trabalho de Conclusão de Curso (Licenciatura em Matemática) - Universidade Estadual da Paraíba, Campina Grande, 2017. 